\title{
Fundación SEFAC: una mano tendida a los pacientes
} y a la población

\author{
Jesús C. Gómez
}

Presidente de SEFAC y la Fundación SEFAC.

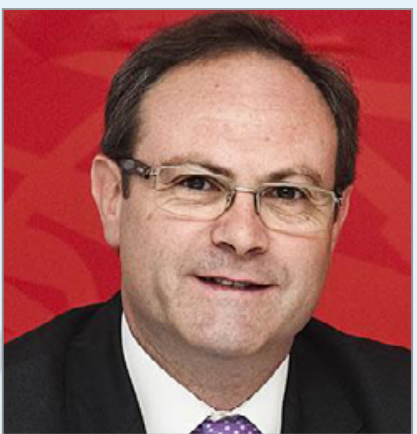

Jesús C. Gómez

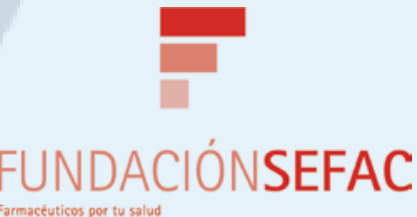

PALABRAS CLAVE

Fundación,

farmacia comunitaria,

farmacéuticos comunitarios, pacientes

\section{KEYWORDS}

Foundation, community pharmacy, community pharmacists, patients
Desde su nacimiento, la Sociedad Española de Farmacia Familiar y Comunitaria (SEFAC) siempre ha estado comprometida con el avance científico y profesional de los farmacéuticos comunitarios. No en vano, SEFAC es una sociedad científica existente en España dirigida en exclusiva a nuestro colectivo con el firme propósito de promover y fomentar, desde sus orígenes, la investigación, la formación y, sobre todo, reforzar la vocación sanitaria de los farmacéuticos mediante el desarrollo de servicios profesionales asistenciales en las farmacias comunitarias. En este marco, y después de casi veinte años de trayectoria, se puede decir que SEFAC se ha consolidado como sociedad científica de referencia para los profesionales de este ramo. Así lo atestiguan los más de 5.400 socios que SEFAC tiene en toda España y los más de 15.000 simpatizantes que participan periódicamente en sus actividades. Del mismo modo, su apuesta decidida por la colaboración interdisciplinar le ha permitido firmar numerosos acuerdos y convenios de colaboración con otras sociedades científicas y llevar la voz de los farmacéuticos comunitarios a foros hasta ahora de difícil acceso o mínima presencia para nuestra profesión. Un ejemplo de esto último es el reciente Marco Estratégico para el desarrollo de la Atención Primaria en el Sistema $\mathrm{Na-}$ cional de Salud.

Pero más allá de su vertiente científica y profesional, la vocación de SEFAC, como la de los profesionales que la integran y a quienes representa, solo tiene razón de ser cuando se enmarca en la consecución de la salud y el bienestar de los pacientes y del conjunto de la población. Esta vertiente asistencial es la que ahora ha llevado a SEFAC a ir más allá en su compromiso, no solo con el avance de los farmacéuticos comunitarios como profesionales de la salud, sino también con la mejora de la atención que reciben los ciudadanos.

Ese paso nuevo se concreta en la creación de la Fundación SEFAC, cuya aprobación se llevó a cabo por la Asamblea de socios celebrada en mayo de 2014 en Málaga y cuya presentación institucional tuvo lugar el pasado 11 de diciembre en Barcelona, ciudad en la que se ubicará su sede. No obstante, ya en octubre de este mismo año la Fundación celebró una primera actividad precisamente en Málaga, donde se aprobó su creación.

La presentación en Barcelona contó con un gran respaldo del sector sanitario y social, materializado en diversos actos que fueron desde la organización de la jornada La farmacia comunitaria, un activo sanitario y social (con representación de ponentes de reconocida valía y diversa procedencia) hasta la celebración de un evento institucional, pasando por la organización de una reunión con las principales asociaciones de pacientes. En esta reunión se dio a conocer a los representantes de los pacientes los principales proyectos de SEFAC en materias de cronicidad, adherencia, historia clínica, etc.

Fueron unos actos de gran repercusión que contaron con la presencia de responsables de la Administración nacional (Ministerio de Sanidad), autonómica (Departament de Salut de la Generalitat) y local (Ayuntamiento). Además de colegios de farmacéuticos, sociedades científicas, universidad, distribución, patronales, industria, medios de comunicación y, en especial, las ya citadas asociaciones de pacientes, que en más de una treintena se dieron cita ese día para acompañar y apoyar este nacimiento, lo que supone, sin duda, un enorme éxito. 


\section{Acercar los valores sociales y sanitarios de la farmacia al paciente}

Si SEFAC tiene sus ojos puestos en la vertiente científica y profesional de los farmacéuticos comunitarios, la Fundación se constituye como el brazo necesario y natural para acercar y difundir la labor asistencial de la farmacia comunitaria a la ciudadanía y canalizar todos aquellos proyectos relacionados con las asociaciones de pacientes. Al tiempo, es una mano tendida para devolver la confianza depositada por los más de dos millones de personas que a diario visitan, en cualquier punto de España, las farmacias comunitarias en busca de sus tratamientos o, simplemente, de algún consejo de salud. La farmacia comunitaria no es solo un activo sanitario de nuestro Sistema Nacional de Salud (la red de farmacias es la mayor red de centros sanitarios del país), sino también un activo social fundamental para la vertebración del territorio y del Estado de Bienestar, pues ya sea en las ciudades o en los pueblos, en los barrios periféricos o en el centro de las urbes, siempre hay farmacias y farmacéuticos comunitarios prestando un servicio de calidad para dispensar e indicar a su comunidad los medicamentos que necesitan con seguridad y eficacia.

La Fundación nace así con la misión de mejorar la calidad de vida de los pacientes y de la población mediante acciones de valor sanitario y social desde la farmacia comunitaria. Además, entre sus fines se encuentran especialmente potenciar la atención farmacéutica y el uso racional del medicamento a todos los ciudadanos, especialmente los que padecen enfermedades crónicas y son más dependientes y vulnerables, tanto desde el punto de vista sanitario como social. Del mismo modo, la Fundación también se dirigirá a impulsar y difundir los servicios profesionales farmacéuticos que mejor contribuyan a la salud, así como a promover y fomentar la docencia, la formación continuada, la educación para la salud y la investigación en el campo de la farmacia comunitaria.

Estos objetivos se traducirán en una serie de actividades, entre las cuales se pueden citar:

- La organización de actividades formativas y conferencias (como las jornadas celebradas en octubre en Málaga y el 11 de diciembre en Barcelona).

- La concesión de premios y becas.

- La organización y celebración de campañas de educación sanitaria dirigidas a la población y a los pacientes.

- El desarrollo de proyectos de investigación en las farmacias comunitarias.

- La promoción de todas aquellas iniciativas que ayuden a acercar la figura del farmacéutico comunitario a la comunidad con la que interactúa.

En definitiva, la Fundación busca contribuir con su nacimiento a mejorar el entorno con el que conviven las farmacias comunitarias a través del conocimiento y los valores de cooperación de la farmacia asistencial que representa SEFAC y que quiere hacer extensivo al conjunto de la ciudadanía. Son muchas las posibilidades que ofrece la creación de la Fundación (de imagen, institucional, cooperación, etc.) y SEFAC quiere aprovecharlas poniendo al servicio de la comunidad los conocimientos y los valores que atesoran los farmacéuticos comunitarios que comparten nuestra filosofía asistencial, porque no se pueden ni se debe olvidar que, tal y como reza el lema de la Fundación, somos farmacéuticos comunitarios para trabajar por la salud de todos los ciudadanos.

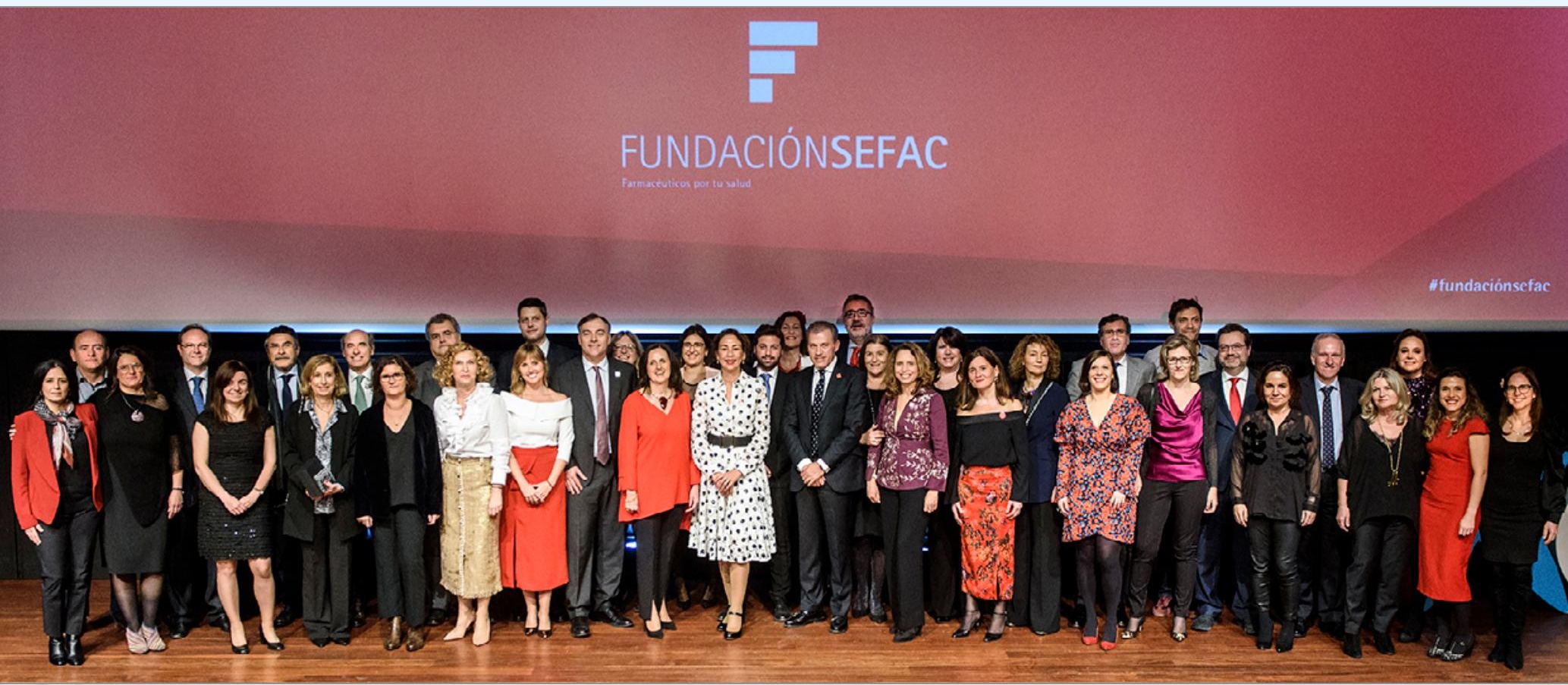

